\title{
CORPOS SONHADOS-VIVIDOS: A DIMENSÃO ONÍRICA DO PODER EM MICHEL FOUCAULT E SUA RELAÇÃO COM A PSICOLOGIA ${ }^{1}$
}

\section{Fernando de Almeida Silveira}

Resumo: A obra de Michel Foucault destaca o corpo, "interpenetrado de história", enquanto expressão das forças de poder e de saber, que se articulam estrategicamente, na história da sociedade ocidental. Na medida em que "o poder é um produtor de individualidade e que o indivíduo é uma produção do poder e do saber", o corpo é uma peça dentro de um jogo de dominações e de submissões, presente em toda a rede social, no processo histórico de produção da subjetividade. Esta pesquisa analisa a dimensão onírica na genealogia de Foucault e visa verificar os efeitos históricos do poder e do saber na construção do imaginário subjetivo, através do corpo, em uma relação recíproca entre o campo da Psicologia e da Filosofia.

Palavras-chave: Foucault, Michel, 1926-1984. Corpo. Alma. Sonho. Subjetivação.

\section{Introdução}

O que primeiramente gostaríamos de destacar é o caráter transdisciplinar desta pesquisa: nossa aproximação com a Filosofia deve ser encarada enquanto uma busca de subsídios mais consistentes para a constituição de uma metodologia da Psicologia que leve em conta as contemporâneas problematizações sobre a edificação não só do sujeito psicológico, mas também do sujeito de conhecimento em geral.

$1 \quad$ Este trabalho originou-se de uma parte da tese de doutorado do autor defendida em 2005: Corpos Sonhados-Vividos:A Questão do Corpo em Foucault e Merleau-Ponty. Meus agradecimentos à Fapesp, pelo financiamento desse projeto de Doutorado e aos professores Reinaldo Furlan, Maria Clotilde Rossetti Ferreira e Étienne Bimbenet. 
Em outras palavras, esta pesquisa tem inspirações, fontes e inter-relações com a Filosofia, mas tem cunho e destinações na Psicologia.

Para tanto, problematizamos a questão do imaginário e da dimensão onírica do sujeito moderno/psicológico no que de mais visceral e encarnado ele possa ter, que é o corpo enquanto materialidade microfísica de acesso e de embate em uma complexa rede de saberes e de poderes que o constitui, o que nos remete a uma certa conformação analítica de inspiração na genealogia foucaultiana, conforme a seguir.

Nossos estudos sobre o corpo em Foucault, desde o Mestrado², nos levaram, introdutoriamente, a considerar que, para Foucault, o poder:

intervém materialmente, atingindo a realidade mais concreta dos indivíduos - o seu corpo - e que se situa ao nível do próprio corpo social, e não acima dele, penetrando na vida cotidiana e por isso podendo ser caracterizado como micropoder ou sub-poder. (Machado, 1979, p.XII)

Essa perspectiva é constantemente direcionada para o desenvolvimento daquilo que se configurou como sendo a microfísica do poder, ou seja, o foco na corporeidade de cada indivíduo - com seus hábitos, instintos, pulsões, sentimentos, emoções, impulsos e vicissitudes - como o ponto fundamental sobre o qual atua um emaranhado complexo de uma série de lutas e de confrontos inerentes a tais saberes, no processo de produção de poder.

Dentre tais práticas, podemos enumerar, ilustrativamente, os suplícios, as disciplinas, as disposições do corpo no tempo e no espaço, os métodos de autoexame e de controle, os mecanismos panópticos de vigilância, os atos e as práticas confessionais (de cunho religioso ou científico), a confecção de laudos periciais e psicológicos sobre as disposições dos corpos e das almas, os exames médicos (que esquadrinham tanto o corpo como a alma dos pacientes, dos loucos, dos excluídos), conceitos de higiene física e de demografia.

É esse conjunto de constatações que se configura enquanto uma nova fase do seu projeto histórico-filosófico, a fase genealógica, enquanto "um diagnóstico que se concentra nas relações de poder, saber e corpo na sociedade moderna" (Rabinow \& Dreyfus, 1995, p. 117).

Essa fase é representada principalmente por Vigiar e Punir (Foucault, 1975/1996), enquanto um estudo que se volta para a constituição dos mecanismos de poder e saber, através da prática penal/punitiva e do im-

2 Sobre a síntese de resultados dessa dissertação, consultar Silveira e Furlan (2003). Aliás, esse novo artigo é avanço e suplemento da temática desse referido artigo, o que justifica sua publicação nessa Revista. 
plemento de fórmulas genéricas de dominação, de cunho disciplinar e de vigilância, presentes em toda a sociedade moderna, e por História da Sexualidade I: a Vontade de Saber (Foucault, 1976/1988), na qual Foucault mostra a implementação do dispositivo da sexualidade.

Dessa maneira, a genealogia foucaultiana foi se revelando como portadora de uma nova estrutura analítica de produção histórico-filosófica, porque reconhece a validade do estudo da corporeidade no que nela se manifesta como mais próximo, também denominada de história efetiva (nitidamente de inspiração nietzscheana): "a história efetiva... lança seus olhares ao que está próximo: o corpo, o sistema nervoso, os alimentos e a digestão, as energias; ela perscruta as decadências" (Machado, 1979, p. 29).

Assim sendo, ao focalizar suas investigações no contexto das singularidades próprias da corporeidade, Foucault passa a relevar como história os eventos e marcas dessa corporeidade os quais, a princípio, são comumente considerados como "não possuindo história, os sentimentos, o amor, a consciência, os instintos" (p. 15).

Nas palavras de Foucault:

O corpo:superfície de inscrição dos acontecimentos (enquanto que a linguagem os marca e as idéias os dissolvem), lugar de dissolução do Eu (que supõe a quimera de uma unidade substancial), volume em perpétua pulverização. A genealogia... está portanto no ponto de articulação do corpo com a história. Ela deve mostrar o corpo inteiramente marcado de história e a história arruinando o corpo. ( p.22)

Em outros termos, o corpo é o campo (porque as forças atravessam e constituem a realidade da corporeidade, não há força sem corpo) de forças múltiplas, convergentes e contraditórias, e o próprio lugar da sedimentação de seus combates.

Ou ainda,

sobre o corpo se encontra o estigma dos acontecimentos passados do mesmo modo que dele nascem os desejos, os desfalecimentos e os erros; nele também eles se atam e de repente se exprimem, mas nele também eles se desatam e entram em luta, se apagam uns aos outros e continuam seu insuperável conflito. (p.22)

Ou seja,

Lá onde a alma pretende se unificar, lá onde o Eu inventa para si uma identidade ou uma coerência, o genealogista parte em busca do começo - dos começos inumeráveis... A marca da proveniência permite dissociar o Eu e fazer pulular nos lugares e recantos de sua síntese vazia, mil acontecimentos agora perdidos. (p. 20) 
Esse caráter dissociativo do eu, com seus começos inumeráveis, múltiplos e dissociadores, possibilita a compreensão de uma dinâmica desse "eu" na qual corpo e alma estão submetidos a processos múltiplos de constituição histórica.

Corpo e alma, portanto, são interpenetrados de história e articulados através de diferentes contextos discursivos, os elementos co-construtores de múltiplos focos de subjetivação, de forma que se torna imprescindível associá-los ao processo de edificação da própria identidade histórica do indivíduo.

Aliás, Foucault "destrona" a alma de sua compleição metafísica ou divina, ou como entidade abstrata, e parte da natureza a-histórica do homem. A alma é elemento focal diretamente produzido junto ao exercício de saber e poder sobre o corpo. O corpo é "superfície de inscrição para o poder, com a semiologia por instrumento; a submissão dos corpos pelo controle das ideias" (Foucault, 1975/1996, p. 93).

Em síntese, Foucault considera "a alma, efeito e instrumento de uma anatomia política: a alma, prisão do corpo" (p. 30, itálicos nossos).

Dessa maneira, ao inverter a clássica proposição platônica quanto ao binômio corpo/alma (lembremos, para Platão, "o corpo é a prisão da alma"), Foucault desnuda o elemento anímico de seu suposto caráter mitificador ou transcendental, pois faz da alma o foco de atuação do poder e saber sobre o corpo - a alma do delinquente, do louco, do aprisionado, do sexualizado, por exemplo - enquanto elemento discursivo-semiótico para o acesso e o exercício dessas forças sobre ele.

Nesse contexto, para Foucault (1996), a alma moderna é"o correlativo atual de uma certa tecnologia do poder sobre o corpo" (p. 31): em síntese, realidade da alma como uma produção sócio-histórica-cultural, através do desenvolvimento de uma série de discursos e saberes, que só têm significado materializado no corpo, em instituições, em práticas sociais. É adesiva aos corpos e comportamentos, mas enquanto realidade histórico-discursiva.

É essa abordagem sócio-histórica do corpo e da alma que consideramos enriquecedora do contexto psicológico enquanto instrumental para renovadas formas de intervenção e de articulação de resistências.

Por sua vez, em estudos recentes do Doutorado, resolvemos abordar a questão do imaginário e dos sonhos a partir da correlação de forças dos poderes e dos saberes, proposta por Foucault. Nosso intuito, ao estabelecermos considerações sobre a dimensão onírica do poder, foi no sentido de uma comunicação efetiva entre Psicologia, Filosofia e História, a partir das já estudadas concepções do corpo e da alma moderna em Foucault, conforme a seguir. 


\section{A Dimensão Onírica dos Poderes e Saberes sobre os Corpos em Foucault}

As enunciações de poder e de saber se rearranjam nos seus embates na história das emergências dos seus afrontamentos desencontrados, atravessando corpos e constituindo a provisoriedade de uma realidade na qual não existe um poder central totalizador, nem indivíduos ou grupos que coordenem centralmente seus encaminhamentos, mas jogos locais, microfísicos e com efeitos corporais, em suas relações desiguais e móveis.

Nesses seus desencontros, fragmentos e resíduos de suas enunciações e práticas disjuntadas criam uma atmosfera onírica, de um desejo de poder exercitado mas nem sempre consumado.

Sob essa ótica, o mundo é, simultaneamente, um campo materialenunciativo para o exercício desses projetos e a grade de especificação, juntamente com a enunciação de corpo, primordial de sua situação.

Nossa perspectiva de relevar a atmosfera onírica na genealogia de Foucault não nos remete a uma hermenêutica das representações dos sonhos dos saberes e poderes, nem a discorrer critérios para as decifrações de seus sentidos, tendentes a fixar as suas imagens fantasiosas em uma relação de correspondência direta entre seus significantes e seus significados.

Nosso intuito é lançá-los para um limiar diverso de uma provável ordem de sua racionalização, contenção ou decifração. Ou seja, enunciar contextos diferentes daqueles em que certo exercício efetivado de dominação se consolida, referentes a amplos mapas de técnicas de poder, plantas arquiteturais panópticas bem diagramadas, tratados de governamentalidades sistematizados, regramentos científicos de biopoder, compêndios de demografia, de higiene e de saúde sexual, dentre outros.

Nosso objetivo é relevar o processo do saber e poder no que nele há de mais indefinido e difuso: seus jogos de exterioridades e de arrebatamentos, os quais tendem a invadir e a cravar corpos, compondo atmosferas delirantes, imprecisas, mas consistentes e ainda não delimitadas.

Partimos da pressuposição de que a atmosfera discursiva da genealogia de Foucault, no que não possa ser codificado nitidamente em um mapa político ou de guerra (ou seja, no que nele ainda seja rarefeito e inconsistente), é a atmosfera do sonho, com suas imagens lacunares, seus movimentos enviesados e seus fluxos e refluxos de potencial possessão sobre os corpos.

Intencionamos, assim, relevar as rupturas e os cortes entre o poder vivido no corpo e o poder almejado enquanto perspectiva (e, portanto, anonimamente sonhado).

Alguns indicadores (sem cunho teórico ou metodológico) podem ser sinalizadores no encaminhamento destas investigações: 
$1^{\circ}$. É importante destacarmos que Foucault se coloca como um estudioso que só produziu "ficções". Ao reconhecer que nunca escreveu "nada além de ficções", simultaneamente acrescenta que não gostaria que "suas" ficções estivessem "fora da verdade", na medida que considera possível "fazer funcionar a ficção no interior da verdade", ou seja, introduzindo "efeitos de verdade num discurso de ficção", a partir de uma realidade política que torne a ficção verdadeira. Em suma,"'ficcionaliza-se' uma política que ainda não existe a partir de uma verdade histórica" (Rabinow \& Dreyfus, 1995, p. 223).

Nesse sentido, podemos também reconhecer, em que pese a gravidade do seu exercício, que os poderes e saberes são ficções dispersas e esparsas na sociedade, efeito de conjunto de uma dinâmica de forças nas quais enunciados e práticas se remetem mutuamente, na constituição de campos de verdades móveis e mutáveis os quais, em seu caráter instável, só deixam de ser ficções enquanto exercidos sobre corpos.

Rememoremos que, se a corporeidade é uma superfície (resistente) de inscrição para os acontecimentos históricos, a noção de marca, assinatura sobre ela cravada (como exercício das várias modalidades da alma moderna), nos transporta à concepção de um exercício ficcional.

Isso se evidencia, por exemplo, no processo de desqualificação histórica do poder do Rei. Se no Classicismo o discurso de mais-poder do Rei sobre os corpos dos supliciados, marcados com menos-poder, era um discurso consistente de realidade e legitimado pelos discursos da onipotência da Majestade na Terra (com seu decorrente imperium de dispor da vida de seus súditos), sua desvalorização, em poucos séculos, pelos dizeres e práticas humanistas, representaram a emergência de novas marcas sobre os corpos, na constituição de um nova concepção de poder, através das mais diversas frentes: livros, jurisprudências, discursos, novos cuidados sobre $o$ corpo e desenvolvimento (principalmente com o advento do capitalismo) de uma extração de forças e de utilidade dos corpos, o biopoder.

Ora, o que vemos nesse desdobramento é um processo de reinversão recíproca: por um lado, a materialização do poder do rei sobre corpos (até então reconhecida como verdade incontestável), sendo paulatinamente minada por multiplicidades de forças que, persistentemente, constituiriam uma nova sensibilidade corpórea (e seu renovado acesso), baseada na transformação da imagem real instituída em um delírio de onipotência. $E$, simultaneamente, a configuração dos ideais humanistas como sonhos em concretização nos corpos.

$2^{\circ}$. No que se refere à nossa concepção de imagem, enquanto análise dos limiares dos corpos marcados num mapa e aqueles ainda não evidentemente marcados, a imagem corporal é uma tessitura histórica de uma marca evidenciada nos jogos de saberes e poderes. Exemplificativamente, a imagem do adúltero, a imagem do homicida, a imagem do menor abandonado como visibilidade no corpo de discursos e práticas. 
Destaca-se que essa conceituação não é remetida a nenhuma noção de interioridade ou de um eu fechado. Ao contrário, a imagem genealógica do corpo é a máxima concretização de um jogo de exterioridades. É a efetivação em um mapa de um exercício de poder e saber.É a confirmação sobre o corpo de uma atmosfera enunciativo-histórica. Portanto, a presença no corpo de uma configuração de poder e saber. Em outras palavras, a imagem enquanto marca adesiva aos corpos, e a ele em pressuposição recíproca.

Ou seja, é um sonho de poder encarnado que tem, na imaginação, seu exercício bélico-estratégico impessoal e anônimo. Se a imagem é expressão mapeada de uma encarnação de poder-saber, por sua vez a imaginação histórica é a atmosfera difusa e dispersa na sociedade como processualidade no acesso de forças sobre corpos. É a imaginação como expressão ficcional de forças em exercício. A imaginação como um campo de delírio fantasioso do poder. Portanto, a imaginação como uma quase-presença de uma configuração de poder e saber, de uma certa ordem desses sonhos que podem se tornar arrazoáveis, tornando o corpo um quase-lugar do seu exercício.

Exemplificativamente, os recentes embates do conservadorismo moral do governo Bush em contraposição ao ideário de liberdade dos democratas, em seu exercício sobre a sexualidade de toda uma nação, como exemplo para o mundo, gerando uma nova atmosfera de conservadorismo, a qual exige que as minorias se rearticulem estrategicamente.

$3^{\circ}$. Se o contexto dos poderes e saberes é composto de forças descontínuas e instáveis, um ideólogo das relações de saber e poder (não afeito à noção de verdade como jogos de ficções) poderá elaborar uma idealização de um exercício do poder mapeado de cunho absoluto. Esse exercício, contraposto à perspectiva genealógica foucaultiana, pregaria a existência de uma relação direta entre a imagem corporal e a imaginação atmosférica do exercício dos poderes e saberes, sem quebras e interstícios.

Esse ideólogo visaria um acesso absoluto dos poderes e saberes sobre os corpos, sem margear espaços para sonhos (constantemente delirantes) de resistência. Intencionaria não só uma posição de corpos fixada e monolítica de uma coletividade em um mapa, como também buscaria uma padronização total das imagens histórico-oníricas microfísicas dos sujeitos tanto sobre suas enunciações e práticas do poder como quanto sobre suas emergentes resistências (também totalmente previsíveis).

Enfim, almejaria não só uma disposição cartográfica precisa e monótona de corpos mapeados, mas uma universalização da capacidade e da potência de sonharmos nossa ambiência histórica e nossa própria identidade corporal.

Sob esse enfoque, muitas vezes Foucault foi considerado um pesquisador que estava "do lado do poder", sem analisar as resistências e suas respectivas linhas de fuga, confundido, portanto, com esse ideólogo absolutista. 
Para nós, a cartografia foucaultiana não é um posicionamento absolutamente objetivador das emanações e da materialidade do corpo em uma cartografia. É, simultaneamente, a visualização de corpos num mapa estratégico e a descrição silenciosa das potenciais dissoluções desse mapeamento. É a transmutação do corpo em um elemento dissolvido em uma ambiência política (e, portanto, geradora de um campo espiritual sobre o que nós somos e o que temos feitos de nós mesmos), de maneira apenas aparentemente contraditória: quanto mais a descrição da fixação dos corpos é evidenciada pelo Foucault genealógico, mais se fazem emergir as conformações delirantes desses sonhos de poder, em suas descontinuidades, reapropriáveis por sonhos reformulados de resistência. Por exemplo, relembremos a maneira delirante com a qual Bush pretendia finalizar a guerra do Iraque em seis meses e os sonhos dos iraquianos resistentes, demolindo esse projeto, como expressão siamesa da ânsia de dominação americana.

Compreendemos que, para Foucault, o corpo é um campo de experiência de multiplicidades de sonhos de verdade. E enquanto preponderantemente sonho, são expressividades absurdas e sem fundamento (dado pelo seu acesso ao corpo).

Os sonhos de verdade seriam, então, fantasias, utopias ou, segundo Foucault (1966/1995), heterotopias. Aliás, para Foucault, as utopias "consolam: é que, se elas não têm lugar real, desabrocham, contudo, num espaço maravilhoso e liso; abrem cidades com vastas avenidas, jardins bem plantados, regiões fáceis, ainda que o acesso seja quimérico." Enquanto que as heterotopias "inquietam", pois"solapam secretamente a linguagem, porque impedem de nomear isto e aquilo, porque fracionam os nomes comuns ou os emaranham". E completa ao supor a razão pela qual "as utopias permitem as fábulas e os discursos: situam-se na linha reta da linguagem, na dimensão fundamental da fábula", enquanto as heterotopias "desfazem os mitos e imprimem esterilidade ao lirismo das frases" (pp.7-8).

Tais sonhos de verdade seriam, também, ficções de poder, sejam mais reacionárias ou transgressoras (aliás, nunca reconhecíveis aprioristicamente). É que os sonhos de poderes e saberes, exercido sobre corpos, podem ser compreendidos na genealogia foucaultiana como uma sequência fractal e fragmentada de enunciados e práticas mais ou menos incoerentes e soltos, os quais emergentemente constituem a alma moderna, no processo de constituição dos corpos.

Aliás, vale a pena retomar e citar essa bela passagem onde Foucault descreve o estatuto da alma moderna:

Não se deveria dizer que a alma é uma ilusão, ou um efeito ideológico, mas afirmar que ela existe, que tem um realidade, que é produzida permanentemente, em torno, na superfície, no interior do corpo pelo funcionamento de um poder que se exerce sobre os que são punidos - de uma maneira geral sobre os que 
são vigiados, treinados e corrigidos, sobre os loucos, as crianças, os escolares, os colonizados, sobre os que são fixados a um aparelho de produção e controlados durante toda a existência. Realidade histórica dessa alma, que, diferentemente da alma representada pela teologia cristã, não nasce faltosa e merecedora de castigo, mas nasce antes de procedimentos de punição, de vigilância, de castigo e de coação. Esta alma real e incorpórea não é absolutamente substância; é o elemento onde se articulam os efeitos de um certo tipo de poder e a referência de um saber, a engrenagem pela qual as relações de poder dão lugar a um saber possível, e o saber reconduz e reforça os efeitos de poder. Sobre essa realidade-referência, vários conceitos foram construídos e campos de análise foram demarcados:psique, subjetividade, personalidade, consciência, etc.; sobre ela técnicas e discursos científicos foram edificados; a partir dela, valorizaram-se as reivindicações morais do humanismo. Mas não devemos nos enganar: a alma, ilusão dos teólogos, não foi substituída por um homem real, objeto de saber, de reflexão filosófica ou de intervenção técnica. $O$ homem de que nos falam e que nos convidam a liberar já é em si mesmo o efeito de uma sujeição bem mais profunda que ele. Uma 'alma' o habita e o leva à existência, que é ela mesma uma peça no domínio exercido pelo poder sobre o corpo. A alma, efeito e instrumento de uma anatomia política; a alma, prisão do corpo. (Foucault, 1975/1996, pp.31-32)

Nesse sentido, a incidência das múltiplas conformações, práticas e enunciativas, da alma moderna sobre os corpos asseguraria um horizonte de configuração de forças com suas respectivas expressividades lacunares, subjetividades plurais, objetiváveis enquanto reapropriações resistenciais conformáveis em novos dispositivos emergentes.

$4^{\circ}$. O poder, enquanto não plenamente cravado sobre a corporeidade, não se verifica completamente, é uma atmosfera onírica que enleva a realidade constituída, ao mesmo tempo em que a acompanha. Ao corpo se oferece, nos seus apelos dispositivos, inclinando-o a seus efeitos, sobre ele se investindo, mas sem sobre ele se acessar plenamente.

Conforme Foucault, esse caráter inclinativo e dispositivo do poder é uma incitação moderna, uma invenção que sobrepujou o caráter diretamente cravado sobre os corpos dos suplícios, com seus efeitos destrutivos e atrozes.

Isso porque essa nova processualidade, no seu movimento insidioso e persistente, acostuma nossos corpos a seus apelos, inclinando-os às suas potenciais disposições, sob o murmúrio sutil e reincidente de seus enunciados disciplinares, prisionais, sexuais, de vigilância, de consumo, dentre outros arranjos.

Esse aspecto persuasivo dos jogos de poder sobre o corpo fica evidente ao Foucault discorrer sobre a sexualidade da sociedade burguesa do século XIX, em que pese o seu discurso puritano, ela submeteria o corpo às suas incitações discursivas, atraindo-o em "espirais onde prazer e poder se reforçam",organizando "lugares de máxima saturação". E que, a pretexto de relevar o despropósito sexual, acaba produzindo conceitos e procedimen- 
tos produtores do que venha a ser a perversidade, de maneira real e direta sobre as corporeidades (Foucault, 1976/1988, p. 47).

Nesse momento, mesmo nos casos da não plenitude de sua consolidação sobre os corpos, ele se realiza enquanto oferta a um conjunto de sedimentação de forças já incidentes, conformadoras de sentidos e de significações, ele se apresenta como um conjunto de contra-sentidos e contra-significações, de caráter desviante e, portanto, atravessando o conjunto de verdades de uma certa realidade constituída historicamente.

Por sua vez, esse seu caráter desviante de uma ordem hegemônica não o torna necessariamente transgressor: pode ser apenas um deslocamento de forças entre arranjos diversos, ambos com efeitos cristalizadores da identidade dos sujeitos e excludentes de suas diferenças.

Nesse sentido, sua funcionalidade estratégica se apresenta como um apelo enunciativo-prático e postural que se insinua na abertura de um novo campo onírico de exercício dos saberes-poderes. No exercício da vontade de saber, a atmosfera de certa conformação de forças é uma apetição que enleva o sujeito, ao mesmo tempo em que o constitui indiretamente na emergência de uma nova corporeidade atmosférica.

É o que exemplificamos atualmente com o advento aparentemente ingênuo e exclusivamente voyeur dos reality-shows, que, a pretexto de uma distração lúdica, nos familiarizam com a sociedade de vigilância que ostensivamente tem se consolidado nas grandes cidades do mundo, com suas câmeras diuturnas, nos prédios e nas ruas, com seus esquadrinhamentos de hábitos e de movimentos de corpos.

Em outras palavras, temos o caráter onírico dos campos lacunares e vagos das forças indefinidas enquanto um caráter de acompanhamento, tal qual o indivíduo, no seu estado de vigília já habituada e incorporada é capaz de, a partir de certo limiar de desatenção e de relaxamento, perceber os apelos de imagens vagas que, antecipadamente, prenunciam as solicitações de mais um período de sono. Nesse sentido, tais imagens em Foucault, por mais residuais que sejam, não são emanações naturais e essenciais de um sujeito, mas produções do campo de embate dos poderes e saberes.

Nesse sentido, mesmo a emanação corpórea mais identificadora de uma pessoa é, em Foucault, sempre fruto de um acompanhamento e/ou incidência de forças.

Ou seja, modernamente os poderes e saberes também passaram a comportar uma atmosfera de produção de sentidos fascinantes. É a sedução do consumo, são os indivíduos dóceis disputando cada vez mais intensa e acriticamente suas colocações de trabalho, são as novelas legitimando a competição entre os indivíduos e a institucionalização muitas vezes padronizada de seus afetos, dentre outros exemplos. Ou incluindo novas condutas, mas sob um prisma constantemente massificador.

Nesse sentido, desejos, vontades e pensamentos são expressões emergentes em uma atmosfera de forças envelopantes. E no interstício re- 
ferente às emanações da alma do sujeito, impregnada dos valores e disposições dessa atmosfera histórica, surge o sujeito como emergência de uma exterioridade que é mais distante do que todo exterior, e de um dentro mais próximo do que qualquer interior.

Nas palavras de Deleuze (1988), uma exterioridade composta pelo "elemento informe das forças". E pelo exterior "como meio dos agenciamentos concretos" (escolas, internações, disciplinamentos, fábricas, conventos, creches, dentre outros), nos quais as relações de força se atualizam. Como também pelas "formas de exterioridade" que se atualizam na cisão e na disjunção emergente entre dois agenciamentos, nas suas interpenetrações (p. 52). É o caso das correlações entre creche e escola, governos municipais e estaduais, vigilância sanitária e hospitais, televisão e família, exemplificativamente.

É nesse emaranhado de entrelaçamentos que se produz a irracionalidade dos embates dos sonhos de poder, nem sempre, como estamos expondo, nitidamente representáveis em um mapa de forças. E mais do que isso, não suscetíveis ao papel moderador da concepção de mapa, já que são rarefações difusas, ambiências afeitas à desordem da devassidão dos sonhos dos saberes e poderes.

É o que Deleuze sinaliza sobre o que ele denomina "superposição de mapas",inerente às correlações variadas entre várias formas de exercício de poder sobre o corpo, algumas delas ilustradas acima. Isso porque, nas suas inter-relações, os vários diagramas de forças comportam, ao lado de seus pontos de conexão, "pontos relativamente livres ou desligados, pontos de criatividade, de mutação, de resistência". Segundo Deleuze, "é deles, talvez, que será preciso partir para se compreender o conjunto" (Deleuze, 1988, p. 53). E, em se tratando de mapeamento, apenas nele esboçáveis enquanto traços soltos, vestígios e rastros, tal qual o indivíduo que pela manhã desperta e relembra as trilhas vagas dos seus sonhos noturnos. Ou seja, é um território de descontinuidades fantasiosas.

Dessa maneira, tanto o sonho em exercício como o sonho em acompanhamento não podem ser considerados como se fossem dois objetos distintos. São duas forças que se constituem mutuamente, e que se manifestam no interstício advindo do excesso de forças que uma posição do sujeito não pode em certo momento comportar, sem que dissolva certo arranjo estratégico preponderante. Por exemplo, é quase sempre inconcebível que um indivíduo seja nazista e sionista ao mesmo tempo, sem dissimulações.

Ou seja, surge daí o corpo como nó inexorável da resistência. A inclinação do sujeito, arrebatado por certa disparidade de ambiências históricas, sempre está exercendo uma posição sócio-histórica, a qual, como vimos, é exclusiva e, portanto, excludente de outros arranjos.

É daí que é impossível uma ideologia do poder como exercício totalizador sobre corpos. No seu aspecto produtivo, os poderes e saberes 
produzem subjetividades, através de uma processualidade que demanda investimento sobre os corpos. É, sob esse prisma, uma certa ascese assujeitadora de corpos e de almas.

Destarte, ocorre a diluição da noção de intencionalidade, pois até mesmo o conceito de resistência é uma prática posicional e provisória, pois somente a experiência de certa encarnação de estratégias permitirá, dentro de certo transcurso histórico, perceber seus efeitos produtores ou não de novas subjetividades.

Nesse sentido, o próprio exercício dos poderes e saberes é um campo de mapeamento em abertura, sujeito a recombinações e a variações que só serão visíveis e perceptíveis no transcurso de determinada temporalidade, a qual, reafirmamos, nem sempre é comportável em certo tempo cultural do relógio. De forma que nem as resistências nem as reincidências dessas forças podem ser previstas aprioristicamente, de forma plena.

Dessa maneira, acreditamos que essa abordagem onírica possa elucidar um dos pontos mais dilemáticos da questão do corpo em Foucault.

Foucault expõe que, para os genealogistas, "nada no homem - nem mesmo seu corpo - é suficientemente fixo para compreender os outros homens e neles se reconhecer" (Machado, 1979, p. 27).

Ora, é bem plausível que se suponha, a partir dessa concepção extremamente maleável da corporeidade que as suas emanações (sentimentos, vontades, desejos), que possam ser transformadas apenas através da incidência de técnicas específicas, as quais, ao redispôr os corpos, transformariam a sensibilidade dele imanente.

Ou seja, os sentidos do corpo seriam simples peças de uma mera maquinaria historicamente constituída. De tal maneira que compreenderíamos que o corpo é redutível a certos arranjos sócio-histórico-culturais. $O$ que nos levaria a conceber, como vimos, o corpo enquanto diretamente atrelado a uma abordagem capitalista, de cunho mecanicista: um corpo absolutamente objetivado e reduzido a uma coisa manipulável.

Acreditamos ser esse um dos efeitos colaterais da redução da analítica foucaultiana a uma abordagem estratégica e belicista, visualizável em mapas, na compreensão de um mapa nitidamente sinalizado, sem o vagar de suas enunciações, aqui denominadas, oníricas.

A relevância do afrontamento de uma dimensão onírica e anônima dos sonhos de poder nos permite conceber a falta de fixação do corpo não do ponto de vista do ideólogo absolutista no exercício de uma redução do corpo a um objeto técnico.

Aliás, a própria concepção de técnicas genéricas de dominação e de submissão do corpo já representaria certa focalização moderna de um sonho de poder em exercício, em um viés já historicamente posicionado e, em certo grau, definido. Nesse sentido, menos afeito às irracionalidades prático-enunciativas dispersas e menos evidenciadas em um mapa de forças. 
É o que Foucault sinaliza ao reconhecer, por exemplo, que as disciplinas sempre foram aplicadas há séculos na Humanidade, nos conventos, nos exércitos, nas oficinas, mas que foi a partir dos séculos XVII e XVIII que se tornaram "fórmulas gerais de dominação",uma ortopedia de corpos num dispositivo de poder e saber (Foucault, 1975/1996, p. 126).

Sob esse prisma, compreendemos que a dimensão onírica dos sonhos de poder é mais multifacetada, com suas efetividades muito soltas e relativamente desconectadas dos corpos.

Acreditamos que a concepção foucaultiana de que nada é fixo no homem, nem mesmo seu corpo, se remete ao âmbito das multiplicidades dos enunciados e das práticas que ainda não foram compartimentalizadas, esquadrinhadas pela perspectiva especializadora do capitalismo moderno, a qual restringe nossos corpos a certas extrações de forças úteis, imediatistas e instantaneístas, voltadas focalizadamente para o consumo de bens e da vida.

Assim, compreendemos que, ao invés de restringir o corpo a dispositivos técnicos absolutamente instrumentalizadores de suas forças, Foucault quebra com o caráter da crônica cotidiana consumista do mundo globalizado e nos lança a um teatro dramático histórico. Enquanto sonhos históricos, possuem suas temporalidades e espacialidades próprias: o teatro dos horrores dos suplícios, as ortopedias minuciosas das disciplinas sobre os corpos, a tragicomédia perversa do dispositivo da sexualidade, a dança tensa estrategicamente resistente dos excluídos e das minorias, dentre outras combinações as quais, por serem objetiváveis, também são delirantes e fantasiosas enquanto não alcançam seus objetivos sobre o corpo.

É daí que advém um dos aspectos destacáveis da analítica de Foucault: a atenção como qualidade fundamental do pesquisador em suas analíticas históricas. Uma atenção que se desdobra não apenas perante o sentido da visão do pesquisador na investigação de um mapa mais ou menos definido, mas a genealogia da atenção dos sujeitos perante os efeitos dos valores históricos sobre o corpo, a atenção enquanto exercício do pensamento que permita que determinado sujeito duvide dos efeitos exteriores da história e da política sobre ele incidentes. A atenção não enquanto elemento psíquico estanque de certo indivíduo, mas enquanto função perceptiva estratégica, que permita que cada um de nós perceba, através de uma ascese de cunho ético e estético (na constituição de uma vida diferenciada dos modelos normalizadores da sociedade de controle moderna), o quanto estamos vigilantes ou alienados diante dos apelos oníricos, atmosféricos e também incorporáveis dos poderes e saberes sobre os corpos.

É assim que reiteramos que, se podemos compreender o mapa como uma genealogia de cartografia de forças mais ou menos estabelecida, a dimensão onírica dos poderes e saberes sobre os corpos tem um cunho oracular, como arte premonitória dos destinos das forças que atuam so- 
bre nossos corpos, de cunho simultaneamente particular e histórico. E, enquanto oráculo, afeito a múltiplos desvios e recombinações.

Não é uma abordagem interpretativa, seja de cunho dos arranjos de nossos inconscientes ou na constituição de imagens estanques e definidas em uma cartilha de sonhos. É o oráculo como a descrição de uma imagem impactante, a percepção de um afeto incidente sobre o consulente do barco da História. As combinações existenciais advindas desse despertar de uma atenção na relação consigo e com os outros é sempre uma articulação em aberto, atualizada a cada instante, sem que a ausência de exterioridades entre os corpos, os poderes e os saberes represente um niilismo fatalista ou uma submissão dos corpos a técnicas totalizadoras.

Pois o sonho do poder, muito mais do que o poder delimitado no mapa, em seu caráter difuso e enfocado sobre os corpos, é a percepção das forças em perspectiva (por isso seu caráter oracular móvel, diagnosticador de mutações), preconizando tanto os caminhos de sua própria fixação ou de sua transposição.

Dreamed-lived bodies: the oneiric dimension of power in Foucault and its relation with the Psychology

\begin{abstract}
Michel Foucault's work highlights body, "interpenetrated by history", as an expression of forces of power and knowledge, which get strategically articulated in the history of occidental society. As "the power is a producer of the individuality and that the individual is a production of the power and knowledge", the body is a piece within a domination and submission play which is present in the whole social network, in the historical process of production of subjectivity. This research analyzes the oneiric dimension in the genealogy of Foucault and it aims to verify the historical effects of the power and knowledge in the construction of the subjective imaginary, through the body, in a reciprocal approach between Psychology and Philosophy fields.
\end{abstract}

Keywords: Foucault, Michael, 1926-1984. Body. Soul. Dream. Subjectivation.

\title{
Corps rêves-vécus: la dimension onirique du povoir chez Michel Foucault et sa relation avec la Psychologie
}

Résumé: Michel Foucault met en relief le corps, "interpénétrée d'histoire", comme l'expression des forces de pouvoir et de savoir, qui s'articulent stratégiquement dans I'histoire de la société occidentale. À mésure que "le pouvoir est producteur de l'individualité et que l'individu est une production du pouvoir 
et du savoir", le corps émerge en tant qu'une pièce dans ce jeu de dominations et de soumissions présent dans tout le reseau social, dans le processus historique de production de la subjectivité. Cette recherche analise la dimension onirique dans le context de la généalogie chez Foucault et il vise à vérifier les effects historiques du pouvoir et du savoir dans la construction de l'imaginaire subjectif, à travers les corps, dans une relation réciproque entre le domaine de la Psychologie et de la Philosophie.

Mots-clés: Foucault, Michel, 1926-1984. Corps. Âme. Rêve. Subjectivation.

\section{Cuerpos soñados-vividos: la dimensión onírica del poder en Michel Foucault y su relación con la Psicología}

Resumen: La obra de Michel Foucault destaca el cuerpo, "interpenetrado por la historia", como expresión de las fuerzas de poder y saber, que se articulan estratégicamente en la historia de la sociedad occidental. En la medida que "el poder es un productor de la individualidad y que el individuo es una producción del poder y del saber", el cuerpo es una pieza dentro de un juego de dominación y sumisión que está presente en toda la red social, en el proceso histórico de producción de subjetividad. Esta investigación examina la dimensión onírica en la genealogía de Foucault y su objetivo es verificar la historia de los efectos de poder y saber en la construcción del imaginario subjetivo, a través del cuerpo, en una relación recíproca entre la Psicología y la Filosofía.

Palabras clave: Foucault, Michael, 1926-1984. Cuerpo. Alma. Sueño. Subjetivación.

\section{Referências}

Deleuze, G. (1988). Foucault (C. Sant'Anna Martins, trad.). São Paulo: Brasiliense.

Dreyfus, H., \& Rabinow, P. (1995). Michel Foucault: uma trajetória filosófica (V. P. Carrero, trad.). Rio de Janeiro: Forense Universitária.

Foucault, M. (1988). História da sexualidade I: a vontade de saber (11a ed., M. T. da Costa Albuquerque \& J. A. Guilhon Albuquerque, trads.). Rio de Janeiro: Graal. (Trabalho original publicado em 1976)

Foucault, M. (1995). As palavras e as coisas (7a ed., S. T. Muchail, trad.). São Paulo: Martins Fontes. (Trabalho original publicado em 1966)

Foucault, M. (1996). Vigiar e punir: nascimento da prisão (14a ed., L. M. Pondé Vassallo, trad.). Petrópolis, RJ: Vozes. (Trabalho original publicado em 1975) 
Machado, R. (Org.). (1979). Microfísica do poder. Rio de Janeiro: Graal. (Edição com base em textos de Michel Foucault)

Silveira, F. A. (2005). Corpos sonhados-vividos: a questão do corpo em Foucault e Merleau-Ponty. Tese de Doutorado, Departamento de Psicologia e Educação, Faculdade de Filosofia Ciências e Letras de Ribeirão Preto, Universidade de São Paulo, Ribeirão Preto, SP. (Disponível em http://www.teses.usp.br/teses/ disponiveis/59/59137/tde-09062006-162253)

Silveira, F. A., \& Furlan, R. (2003). Corpo e alma em Foucault - postulados para uma metodologia da psicologia. Psicologia USP, 14(3), 171-194. Recuperado da Scielo (Scientific Electronic Library Online): http://www.scielo.br/pdf/pusp/v14n3/ v14n3a12.pdf

Fernando de Almeida Silveira, professor Adjunto de Psicologia e Humanismo e de Ética da Universidade Federal de São Paulo - Campus Baixada Santista. Doutor em Psicologia pela Faculdade de Filosofia, Ciências e Letras de Ribeirão Preto, Departamento de Psicologia e Educação da USP - Ribeirão Preto. Pós-Doutor em Filosofia - Departamento de Filosofia e Metodologia das Ciências - UFSCar - São Carlos. Endereço para correspondência: Universidade Federal de São Paulo - Campus Baixada Santista. Avenida Almirante Saldanha da Gama, 88/89 - Ponta da Praia - Santos - CEP 11030-400. Endereço eletrônico: fernando.silveira@unifesp.br

Recebido em: 9/10/2007

Aceito em: 5/06/2008 